\title{
DEVELOPMENT AND VALIDATION OF A HPLC METHOD FOR THE SIMULTANEOUS DETERMINATION OF PSEUDOEPHEDRINE, DEXTROMETHORPHAN, AND TRIPROLIDINE IN THEIR COMBINED COUGH AND COLD SYRUPS
}

\author{
Imad Osman Abu Reid ${ }^{\mathrm{a}^{*}}$ and Elrasheed Ahmed Gadkariem ${ }^{\mathrm{a}}$ \\ ${ }^{a}$ Department of Pharmaceutical Chemistry, Al Ribat National University, Khartoum, Sudan \\ * iabureid@hotmail.com
}

\section{ABSTRACT}

A simple and efficient liquid chromatographic method has been developed and validated for the simultaneous determination of pseudoephedrine, dextromethorphan, and triprolidine in cough and cold syrup. The separation of the analytes was achieved within $10 \mathrm{~min}$, employing a mixture of $50 \% \mathrm{v} / \mathrm{v}$ methanol-water containing $35.07 \mathrm{mM} / \mathrm{L}$ ammonium acetate adjusted to $\mathrm{pH} 5.58$ as isocratic mobile phase, pumped at $1.0 \mathrm{ml} \mathrm{min}^{-1}$ through a strong cation exchange column $(10 \mu \mathrm{m}$ particle size). The analytes were detected at $265 \mathrm{~nm}$. Statistical experimental designs and graphic representations (response surface methodologies, Pareto charts) were used for optimizing the mobile phase composition. The linearity of the calibration $(r>0.99, n=18)$ in the relevant ranges (up to $125 \%$ of the expected concentrations of the analytes in the formulation), method accuracy (RSD $<2.0 \%)$, repeatability $(\mathrm{RSD}<2.0 \%)$ and intermediate precision, were verified. System suitability parameters were also determined. The validated method was successfully employed for the routine analysis of a syrup pharmaceutical preparation against cough and cold, showing satisfactory analytes recoveries and precsion.

\section{Keywords}

Pseudoephedrine, Dextromethorphan, Triprolidine, Experimental design, Cation exchange column.

\section{INTRODUCTION}

Cough and cold medications usually contain a complex mixture of nitrogenous compounds as active ingredients. These are usually present in varying and very different proportions, have diverse properties inherent to their formulation and desired action, and often possess some similar physical and chemical properties, which turns their separation difficult. Moreover, in the case of HPLC analysis, these basic drugs strongly interact with the reversed-phase stationary materials, causing peak asymmetry and lowering separation efficiency [1]. Due to these characteristics, quality control of preparations against the cough and cold always offers an interesting analytical challenge [2].

Pseudoephedrine (PS), triprolidine (TR), and dextromethorphan (DX) are nitrogenous compounds (Figure 1) widely used as active ingredients in combined cold medicine formulations due to their decongestant (PS), antihistaminic (TR) and cough suppressant (DX) activities [3]. Their commercial associations exhibit important mass differences among the analytes (PS:TR up to $24: 1, \mathrm{w} / \mathrm{w}$ ), in addition being liquids common formulations of these products require addition of preservatives such as methylparaben (MP), prorylparaben (PP), or sodium benzoate (SB). All these aspects increase the analytical challenge.

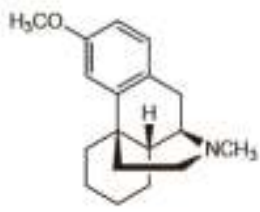

Dextromethorphan (DX)

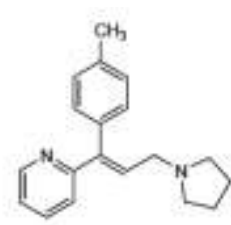

Triprolidine (TR)<smiles>CN[C@@H](C)C(O)c1ccccc1</smiles>

Pseudoephedrine (PS)

Fig 1: Chemical structures of dextromethorphan, triprolidine, and pseudoephedrine.

The use of strong cation exchanger (SCX) materials, such as propylsulfonic acid, which are highly acidic $\left(\mathrm{pK}_{\mathrm{a}}<1\right)$ and effectively ionized at all $\mathrm{pH}$ values, makes the development of separations for basic compounds relatively straightforward, besides its other advantage related to its specificity for the analysis of basic compounds when present in mixture with acidic/neutral compounds as the latter are either not retained or poorly retained [4-6].

Literature survey revealed the interest in the determination of PS, TR, and DX in pharmaceutical formulations either alone or in combination with other active principles [7-29]. The simultaneous analysis of the three components has been performed by a few methods only, including UV spectrophotometry [30-32] and HPLC [33].

The objective of the present work was to develop and validate a high-performance chromatographic methodology for the simultaneous determination of PS, DX, and TR in their combined syrup formulations, using cation-exchange stationary phase. Experimental design techniques as a rational, cost-effective and convenient tool to speed up the process were employed for development of the proposed method [34].

The novelty of the proposed method stems from its ability within a reasonable analysis time, to separate such a complex mixture without interference from the co-formulated additives and without prior sample pre-treatment. The cost effectiveness of the method in term of using inexpensive reagents and chemicals is another benefit added. 


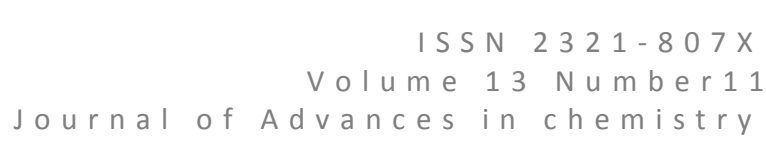

\section{MATERIALS AND METHODS}

\subsection{Apparatus and Software}

Experiments were performed on a Shimadzu Prominence HPLC system consisted of: degasser (Model DGU-20A5), pump (Model LC-20AD), Rheodyne manual injector fitted with $20 \mu \mathrm{l} \mathrm{loop,} \mathrm{variable} \mathrm{wavelength} \mathrm{UV-Vis} \mathrm{detector} \mathrm{(ModelSPD-20A).}$

Experimental design, data analysis and desirability function calculations were performed by using Design-Expert ${ }^{\circledR}$ trial version7.0.0. (Stat-Ease Inc., Minneapolis). Statistical analyses were carried using Microsoft Excel 2013 software (Microsoft, USA).

\subsection{Reagents and Materials}

Analytical grade reagents: ammonium acetate (E. Merck, Germany), glacial acetic acid (Scharlau Chemie, Spain), HPLCgrade methanol (Scharlau Chemie, Spain) and double-distilled water were employed for the preparation of the samples and for chromatographic analysis.

Pseudoephedrine hydrochloride, dextromethorphan hydrobromide and triprolidine hydrochloride working standards (99.1\%, $99.3 \%$, and 99.6\%, respectively), were kindly provided by Amipharma Laboratories, Sudan. Unifed DM Syrup (Labeled to contain: Triprolidine $\mathrm{HCl} 1.25 \mathrm{mg}$, Pseudoephedrine $\mathrm{HCl} 30 \mathrm{mg}$ and Dextromethorphan $\mathrm{HBr} 10 \mathrm{mg}$ per each 5 $\mathrm{ml}$ ) was purchased from local market.

\subsection{Preparation of Solutions}

\subsubsection{Optimization Standard}

One $\mathrm{ml}$ from a stock solution containing $1.3 \mathrm{mg} / \mathrm{mL}$ of triprolidine $\mathrm{HCl}$ and $1.0 \mathrm{mg} / \mathrm{mL}$ of prorylparaben (PP) in methanol was transferred into a $20 \mathrm{ml}$ volumetric flask containing accurately weighed about $35 \mathrm{mg}$ pseudoephedrine $\mathrm{HCl}$ and $20 \mathrm{mg}$ dextromethorphan $\mathrm{HBr}$. To this mixture $10 \mathrm{~mL}$ of $50 \% \mathrm{v} / \mathrm{v}$ aqueous methanol diluent were added, content of the flask was sonicated for 5 minutes, cooled and made to mark using the same diluent.

\subsubsection{Stock standard solution}

Stock standard solution was prepared by initially dissolving accurately weighed about $180 \mathrm{mg}$ pseudoephedrine $\mathrm{HCl}, 10$ $\mathrm{mg}$ triprolidine $\mathrm{HCl}$ and $60 \mathrm{mg}$ dextromethorphan $\mathrm{HBr}$ in $20 \mathrm{~mL}$ volumetric flask using $10 \mathrm{~mL}$ of $50 \%$ v/v aqueous methanol diluent. The content of the flask was then sonicated for 5 minutes, cooled and adjusted to mark using the same diluent.

Other standard solutions were prepared by proper dilution of aliquots from the stock standard solution with $50 \% \mathrm{v} / \mathrm{v}$ aqueous methanol.

\subsubsection{Working standard solution}

Working standard solution containing PS $(1800 \mu \mathrm{g} / \mathrm{mL})$, TR $(100 \mu \mathrm{g} / \mathrm{mL})$ and $\mathrm{DX}(600 \mu \mathrm{g} / \mathrm{mL})$ was freshly prepared by diluting $10 \mathrm{ml}$ of stock standard solutions to $50 \mathrm{ml}$ with $50 \%$ aqueous methanol.

\subsubsection{Sample preparation}

The sample density was determined and then sample weight accurately equivalent to $5 \mathrm{~mL}$ was taken in $20 \mathrm{~mL}$ volumetric flask, $10 \mathrm{~mL}$ of $50 \%$ aqueous methanol diluent were added and sample was then sonicated for 5 minutes, cooled and made to mark using same diluent. The sample was filtered through $0.45 \mu \mathrm{m}$ nylon filter and $20 \mu \mathrm{l}$ were injected into the HPLC system.

\subsubsection{Chromatographic Procedure}

Chromatographic separations were carried out on a Partisil 10 SCX column $(10 \mu \mathrm{m}$ particle size, $250 \mathrm{~mm} \times 4.6 \mathrm{~mm}$ I.D.).During the optimization experiments the mobile phases were prepared to contain different proportions of methanolwater-ammonium acetate, the $\mathrm{pH}$ of the mobile phases was adjusted with $10 \%$ glacial acetic acid. The detection wavelength was set to $265 \mathrm{~nm}$ to obtain maximum sensitivity for quantitation of triprolidine since it is present in small amount in the product; pseudoephedrine and dextromethorphan were also monitored at this wavelength. $20 \mu \mathrm{l}$ were injection volumes were used throughout the experimental work.

\subsubsection{Validation}

The optimized method was validated in according to the ICH guideline [35], the method linearity in the relevant working ranges, precision, and accuracy were evaluated. System suitability parameters were also determined.

\section{RESULTS AND DISCUSSION}

\subsection{Optimization Design and Analysis}

Before starting an optimization procedure, the curvature term was investigated using factorial design with center points investigates. ANOVA generated for $2^{k}$ factorial design showed that curvature is significant for all the responses (the resolution between each pair of adjacent analytes peaks ) since p-value was less than 0.05 . This implies that quadratic 
should be considered to model the separation process [36]. In order to obtain second order predictive model Box-Behnken design was employed [37]. The optimum composition of the mobile phase was determined with series of mobile phases containing water: methanol mixtrues in the range of $(45-50 \% \mathrm{v} / \mathrm{v})$ containing ammonium acetate $(35-45 \mathrm{mM} / \mathrm{L})$ with the $\mathrm{pH}$ being varied between 5-6.

Derringer's desirability function was used to optimize this process since the process involves optimization of three responses at a time [38]. The resolutions between adjacent peak pairs were the responses considered for the purpose of optimization. The use of response surface methodologies (Figure 2) indicated that the optimum mobile phase composition was $50 \% \mathrm{v} / \mathrm{v}$ methanol-water mixture having ionic strength $35.07 \mathrm{mM} / \mathrm{L}$ and $\mathrm{pH} 5.58$.

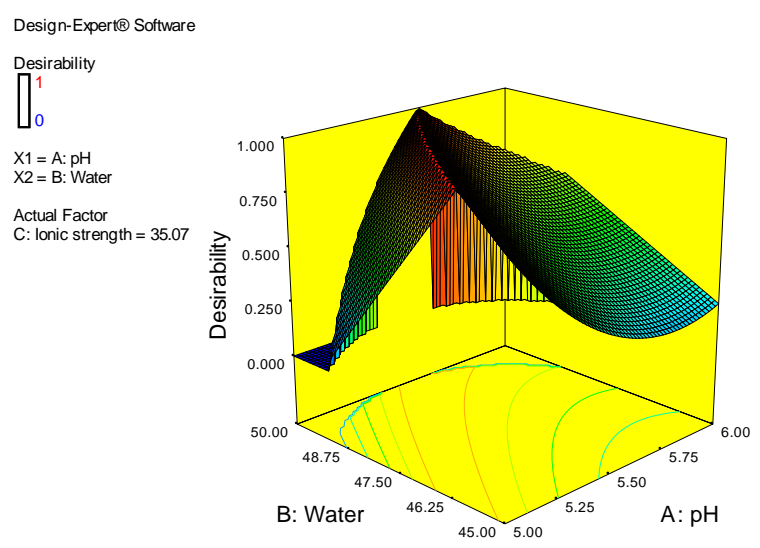

Fig 2: Graphical representation of overall desirability function $D(=1.0)$ were $\mathrm{pH}(\mathrm{A})$ of 5.58 , methanol-water $(B)$ of $50 \% \mathrm{v} / \mathrm{v}$, and ionic strength (C) of $35.07 \mathrm{mM} / \mathrm{L}$

Figure 3 shows a representative chromatogram of the optimization standard, standard solution, and real sample under the optimized conditions, where baseline separation of the relevant analytes was achieved within a reasonable time.

The elution order of the analytes from the column was PS , DX and TR respectively; this order of elution can be related to their acid dissociation constants $\left(\mathrm{pk}_{\mathrm{a}}\right)$ since PS $\left(\mathrm{pk}_{\mathrm{a}}=9.8\right), \mathrm{DX}\left(\mathrm{pk}_{\mathrm{a}}=8.3\right)$ and TR $\left(\mathrm{pk}_{\mathrm{a}}=6.5\right)$ [39]. PS being the storgest base among the three compounds was eluted first, followed by DX and TR respectively, under the optimized experimental conditions. This finding is consistent with the earlier observation [40], that if two bases are fully protonated then the stronger base is eluted before (has less affinity for the stationary phase) than the weaker one.

Based on this finding it is possible to predict the elution order of basic compounds in a mixture under cation exchange conditions through the knowdeldge of their $\mathrm{pk}_{\mathrm{a}}$ value, moreover this property can be used to adjust selectivity by proper selection of the mobile phase $\mathrm{pH}$ and manipulating its ionic strength and aqueous/organic ratio .
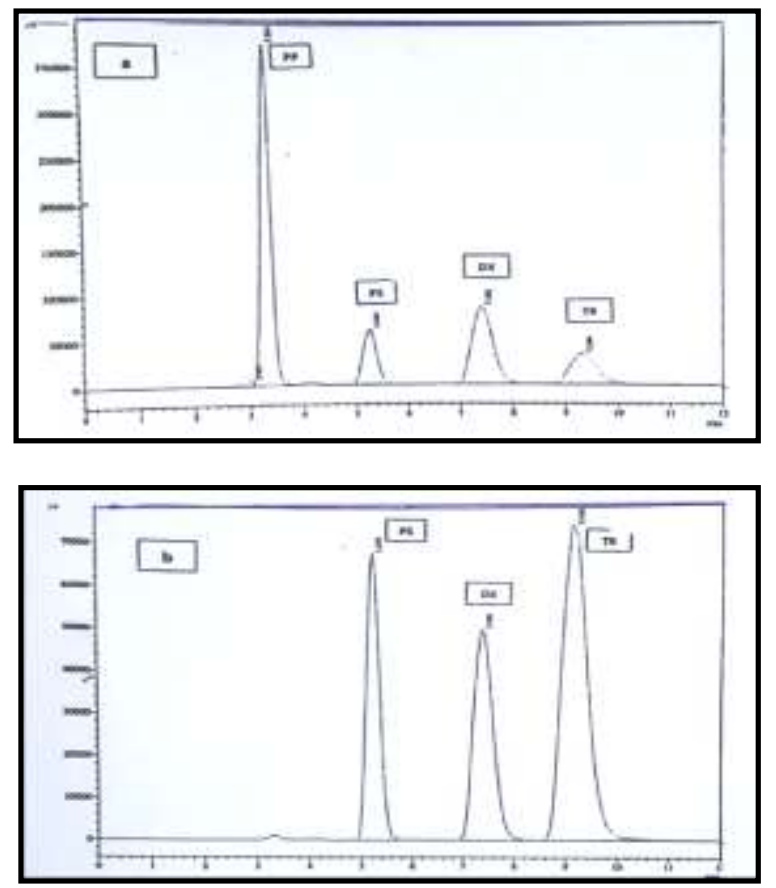


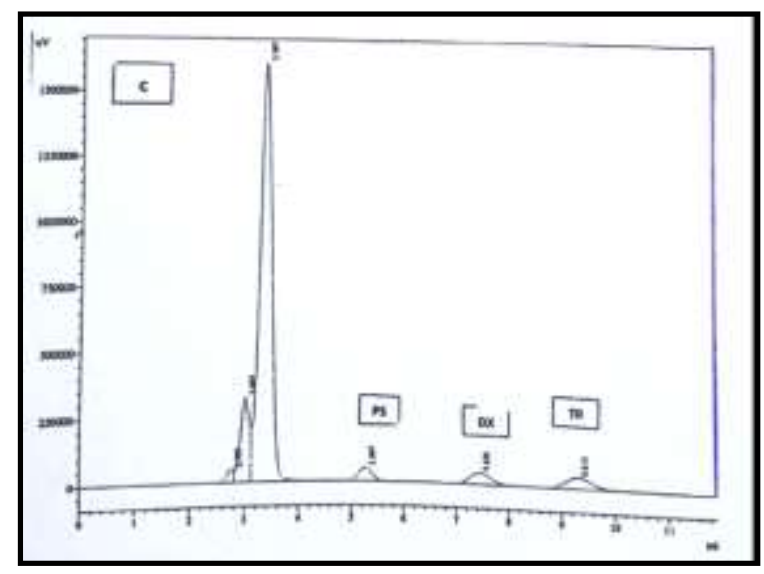

Fig 3: Chromatograms corresponding to a) optimization standard, b) standard solution, c) real sample (Unifed Syrup) , under optimum conditions (methanol-water $=50 \% \mathrm{v} / \mathrm{v}$, ionic strength $=35.07 \mathrm{mM} / \mathrm{L}$, and $\mathrm{pH}=5.58$ )

\subsection{Method Validation}

The optimized method was validated in agreement with the $\mathrm{ICH}$ guideline [35]. Accordingly, method linearity in the relevant working ranges, precision and accuracy were evaluated. System suitability was also determined.

\subsubsection{Range and Linearity}

Method range and linearity were evaluated with six mixtures of standards at the following concentrations: $188.0-1880.0$ $\mu \mathrm{g} / \mathrm{ml} \mathrm{PSE}, 61.3-613.0 \mu \mathrm{g} / \mathrm{ml} \mathrm{DX}$, and $8.60-86.0 \mu \mathrm{g} / \mathrm{ml}$ of TR, covering up to $125 \%$ of the expected concentration of the analytes in the formulation. Samples were injected in triplicate and calibrations were obtained by plotting the standard drug concentrations versus peak areas of the individual drugs. The calibration curves were defined by the equations shown in Table 1, and the residuals were spread uniformly and at random around the regression lines, passing the normality distribution test $(p<0.05)$. In addition, correlation coefficients were higher than 0.99 and the confidence intervals of the intercepts contained the zero, confirming method linearity.

\subsubsection{Precision}

Method precision was verified in its repeatability and intermediate precision aspects according to the ICH guideline Q2 (R1) [35]. Six replicate determinations of the samples containing $100 \%$ of their corresponding expected concentrations in the pharmaceutical product were injected and the relative standard deviation (RSD) of their recoveries was determined. The observed RSD levels (Table 1), which were below $2 \%$, were considered satisfactory. For verification of the intermediate precision the process was repeated on another day using fresh reagents and samples, the samples were injected at random during two different days. This evidenced that the outcome of the determination was statistically similar regardless the day of the assay and the reagents preparation in the determinations. In addition, in all cases almost quantitative and consistent $(\mathrm{RSD}<2 \%)$ drug recoveries were recorded [41]. These results confirmed that the method is precise.

Table 1: Results of Method validation

\begin{tabular}{|c|c|c|c|}
\hline Parameter & PSE & $\mathbf{D X}$ & TR \\
\hline Number of calibration standards & 6 & 6 & 6 \\
\hline Concentration range $(\mu \mathrm{g} / \mathrm{ml})$ & $188.0-1880.0$ & $61.3-613.0$ & $8.60-86.0$ \\
\hline \multicolumn{4}{|l|}{ Linearity - Regression equation } \\
\hline Slope (b) & 629.33 & 2465.57 & 25805.59 \\
\hline Intercept (a) & 9627.69 & 12200.08 & 9981.27 \\
\hline Correlation coefficient $\left(r^{2}\right)$ & 0.9998 & 0.9998 & 0.9996 \\
\hline Standard deviation of the slope $\left(\mathrm{s}_{\mathrm{b}}\right)$ & 6.59 & 24.23 & 267.13 \\
\hline Standard deviation of the intercept $\left(\mathrm{s}_{\mathrm{a}}\right)$ & 7527.72 & 9014.96 & 13960.82 \\
\hline \multicolumn{4}{|l|}{ Precision } \\
\hline Repeatability (recovery $\% \pm S D)^{a}$ & $98.46 \pm 0.83$ & $100.27 \pm 0.64$ & $104.10 \pm 1.04$ \\
\hline 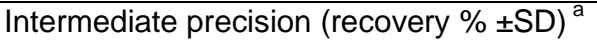 & $98.62 \pm 0.85$ & $100.10 \pm 0.64$ & $103.79 \pm 0.54$ \\
\hline Overall analyte recovery $\%( \pm S D)$ & $98.54 \pm 0.82$ & $100.19 \pm 0.62$ & $103.95 \pm 0.78$ \\
\hline
\end{tabular}




\begin{tabular}{|c|c|c|c|}
\hline Accuracy (recovery $\% \pm$ SD) ${ }^{b}$ & $101.46 \pm 0.51$ & $98.72 \pm 0.32$ & $104.01 \pm 0.61$ \\
\hline Limit of detection $(\mu \mathrm{g} / \mathrm{ml})$ & 50.73 & 15.51 & 2.27 \\
\hline Limit of quantitation $(\mu \mathrm{g} / \mathrm{ml})$ & 153.72 & 46.99 & 6.88 \\
\hline
\end{tabular}

${ }^{a}$ Six replicates of sample at $100 \%$ level. ${ }^{\text {b }}$ Triplicate injections of three independent sets of samples at six levels.

\subsubsection{Accuracy}

Method accuracy was demonstrated using standard addition method by evaluating analyte recoveries from a pre-assayed pharmaceutical formulation sample, containing $60 \%$ of the declared amounts of the drugs, which was fortified with known amounts of the three analytes, to reach concentration levels of $60 \%-120 \%$ of the expected drug concentrations in the pharmaceutical dosage form. The observed RSD levels (Table 1), which were below $2 \%$, were considered satisfactory. This confirmed that the method enables the accurate determination of the analytes [41].

\subsubsection{Limits of Detection LOD and Quantification LOQ}

In order to assess that the validated concentration ranges of the analytes were above their $L O Q$ values, the LOD and LOQ were determined employing the ICH method based on the calibration curve [35]. The LOD values were $50.73 \mu \mathrm{g} / \mathrm{ml}$ for PSE, $15.51 \mu \mathrm{g} / \mathrm{ml}$ for DX, and $2.27 \mu \mathrm{g} / \mathrm{ml}$ for TR; the corresponding LOQ values, determined by the use of the same method, were 153.72, 46.99, and $6.88 \mu \mathrm{g} / \mathrm{ml}$, respectively. These values fall below the lowest expected analyte concentrations in the samples.

\subsubsection{System Suitability Parameters}

System suitability parameters must be checked to ensure that the system is working correctly during the analysis. The test was carried out by injecting five replicates of the optimization standard. The method performance data including column efficiencies $(N)$, resolutions between adjacent peeks $\left(R_{s}\right)$, and asymmetry factor $\left(A_{s}\right)$ are listed in Table 2 . All the parameters were in good agreements with the theoretically required ones [42].

Table 2: System Suitability Parameters from Optimization Mixture Analysis

\begin{tabular}{|c|c|c|c|}
\hline Analyte & Resolution $\left(R_{s}\right)$ & Asymmetry factor $\left(A_{s}\right)$ & Theoretical plates \\
\hline PS & $5.33 \pm 0.2^{*}$ & 1.09 & 3670.8 \\
\hline $\mathrm{DX}$ & $3.77 \pm 0.3^{* *}$ & 1.16 & 3383.2 \\
\hline \multirow[t]{2}{*}{ TR } & $2.38 \pm 0.4^{* *}$ & 1.21 & 3314.8 \\
\hline & \multicolumn{3}{|c|}{${ }^{* *}$ resolution between $\mathrm{PS}$ and DX } \\
\hline
\end{tabular}

\section{CONCLUSION}

A reliable and rapid liquid chromatography method for the simultaneous determination of PSE, DX, and PSE in syrup has been developed and validated. Experimental designs were employed for rational method optimization and demonstration of its suitability for the intended purpose. The use of strong cation exchange column enabled separation of the active principles within $10 \mathrm{~min}$, despite their widely different properties; using very simple, relatively cheap and easy to prepare mobile phase. It was also possible to achieve their quantification in spite of the important abundance differences among the analytes (PSE: TR up to 24:1, w/w). In addition, the results indicate that the method is sensitive, linear, precise, and accurate, with regards to the mixture under investigation. Therefore, the method can be safely applied to the quality control of combined cough and cold medicines containing PSE, DX, and TR.

\section{Conflict of interest}

Authors do not have any conflict of interest with the commercial identities mentioned in this article.

\section{REFERENCES}

1. L. Suntornsuk, O. Pipitharome, P. Wilairat, Simultaneous Determination of Paracetamol and Chlorpheniramine Maleate by Micellar Electrokinetic Chromatography. J Pharm Biomed Anal. 33, 441-449 (2003).

2. N. Borkar, S. Sawant, Review of Simultaneous Determination of Analytes by High Performance Liquid Chromatography (HLPC) in Multicomponent Cough and Cold Oral Drug Products. Int. J. Pharm. Tech. Res. 3, 1339-1345 (2011).

3. S. Sweetman, Martindale: The Complete Drug Reference, The Pharmaceutical Press. (London, 2009). 
4. B. Law, JRG. Appleby, Re-evaluation of strong cation-exchange high-performance liquid chromatography for the analysis of basic drugs. J. Chromatogr. A. 725, 335-341 (1996)

5. R.J. Flanagan, E.J. Harvey, E.P. Spencer, HPLC of basic drugs on microparticulate strong cation-exchange materials - a review. Fore. Sci. Int. 121, 97-102 (2001).

6. Z. Long, C. Wang, Z. Guo, X. Zhang, L. Nordahl, X. Liang, Strong cation exchange column allow for symmetrical peak shape and increased sample loading in the separation of basic compounds. J. Chromatogr. A. 1256, 67-71 (2012).

7. L. Sriphong, A. Chaidedgumjorn, K. Chaisuroj, Derivative Spectrophotometry Applied to the Determination of Triprolidine Hydrochloride and Pseudoephedrine Hydrochloride in Tablets and Dissolution Testing.World Academy of Science, Engineering and Technology. 55, 573-577 (2009).

8. R. Moharana, N. Kawathekar, S.C. Chaturvedi, Simultaneous Spectrophotometric Estimation Of Triprolidine Hydrochloride And Pseudoephedrine Hydrochloride In Pharmaceutical Dosage Form. Indian J Pharm. Sci . 58, 93-95 (1996)

9. M.J. Akhtar, S. Khan, M. Hafiz, High-performance liquid chromatographic assay for the determination of paracetamol, pseudoephedrine hydrochloride and triprolidine hydrochloride. J. Pharm. Biomed. Anal. 12, 379382 (1994).

10. D.B. Wanjari, V.V. Parashar, S.N. Lulay, M.R. Tajne, N.J. Gaikwad, Simultaneous HPLC estimation of acetaminophen, chlopheniramine maleate, dextromethorphan hydrobromide and pseudoephedrine hydrochloride in tablets. Indian J. of Pharm. Sci. 66, 345-347 (2004).

11. K.C. Marcus, J.H. Ira, A.F. Salvatore, Ion-Pair Reversed-Phase High-pressure Liquid Chromatography of Cough-Cold Syrups I: Pseudoephedrine Hydrochloride, Brompheniramine Maleate, and Dextromethorphan Hydrobromide. J. Pharm. Sci. 68,1463-1464 (1979).

12. F. Al-Rimawi, Normal-phase LC method for simultaneous analysis of pseudophedrine hydrochloride, dextromethorphan hydrobromide, chlorpheniramine maleate, and paracetamol in tablet formulations. Saudi Pharm. J. 18, 103-106 (2010).

13. M. Qi, P. Wang, L. Zhou, Y. Sun, Simultaneous Determination of Four Active Components in a Compound Formulation by Liquid Chromatography. Chromatographia. 58, 183-186 (2003).

14. A. Manassra, M. Khamis, M. El-Dakiky, Z. Abdel-Qader, F. Al-Rimawi, Simultaneous HPLC analysis of pseudophedrine hydrochloride, codeine phosphate, and triprolidine hydrochloride in liquid dosage forms. J Pharm. and Biomed. Anal. 51, 991-993 (2010).

15. M.S. Ali, M. Ghori, S. Rafiuddin, A.R. Khatri, A new hydrophilic interaction liquid chromatographic (HILIC) procedure for the simultaneous determination of pseudoephedrine hydrochloride (PSH), diphenhydramine hydrochloride (DPH) and dextromethorphan hydrobromide (DXH) in cough-cold formulations. J Pharm. Biomed. Anal. 43,158-167 (2007).

16. C. Lei, N. Nan, Determination of Four Main Ingredients in Photifed -M Children Cough Syrup. Chinese J of Pharm. Anal. 24,44-45 (2004).

17. B. Aşçı, O.A. Dönmez, A. Bozdoğan , S. Sungur, Simultaneous determination of paracetamol, pseudoephedrine hydrochloride, and dextromethorphan hydrobromide in tablets using multivariate calibration methods coupled with HPLC-DAD. J. Liq. Chromatog. Related Tech. 4, 1686-1698 (2011).

18. H. Al-akraa, N. Sarkis, M Alshehaby, New rapid RP-HPLC method for simultaneous determination of some decongestants and cough-sedatives. Intern. J. Pharm. Pharm. Sci. 5, 234-241 (2013).

19. M.R. Louhaichi, S. Jebali , M.H. Loueslati, N. Adhoum , L. Monser, Simultaneous determination of pseudoephdrine, pheniramine, guaifenisin, pyrilamine, chlorpheniramine and dextromethorphan in cough and cold medicines by high performance liquid chromatography. Talanta. 78, 991-997 (2009).

20. U.R. Mallu, V. Bobbarala, S. Penumajji, Analysis of cough and analgesic range of pharmaceutical active ingredients using RP-HPLC. Intern. J. Pharma and Bio Sci. 2, 439-452 (2011).

21. Y. El-Shabrawy, A. El-Gindy, M.A. Shoeib, Y. El-Gindy, An HPLC Method for Determination of 15 Pharmaceutical Compounds in Anti-Cold Products. Standard Research J. Pharm. Pharmacol. 1, 86-94 (2014).

22. M.D. Pacioll, S.A. Jansen, S.A. Martellucci, A.A. Osei, A fast and efficient determination of amines and preservatives in cough and cold liquid and suspension formulations using a single isocratic ion-pairing high power liquid chromatography method. J. Pharm. Biomed. Anal. 26,143-149 (2001).

23. R.K. Venisetty, S.K. Kumar, RP-HPLC Method Development and Validation for Simultaneous Estimation of Dextromethorphan, Phenylephrine and Triprolidine in Bulk and its Application in Evaluation of Marketed Tablet Dosage Forms. Int J of Adv. Biomed \& Pharm Res. 3,14-18 (2014).

24. T. Harsono , M. Yuwono, G. Indrayar, Simultaneous determination of some active ingredients in cough-cold preparations by gas chromatography. JAOAC Int. 88, 1093-1098 (2005). 
25. O. Lau, Y. Cheung, Simultaneous determination of some active ingredients in cough-cold syrups by gas-liquid chromatography. Analyst. 115, 1349-1353 (1990)

26. Dong, X. Chen, Y. Chen, X. Chen, Z. Hu, Separation and determination of pseudoephedrine, dextromethorphan, diphenhydramine and chlorpheniramine in cold medicines by nonaqueous capillary electrophoresis. J. Pharm. Biomed. Anal. 39, 285-289 (2005).

27. S. Di Berardino, R. Jasionowska, Rapid and Sensitive CZE Method for Quality Control Analysis of Pharmaceuticals Containing Pseudoephedrine, Triprolidine and Paracetamol. American J. Anal. Chem. 5, 613619 (2014).

28. L. Zhang, Q. Hu, G. Chen, Y. Fang, Simultaneous determination of the active ingredients in composite pseudoephedrine hydrochloride tablets by capillary electrophoresis. Anal. Chim. Acta. 424, 257-262 (2000).

29. J.L. Murtha, T.N. Julian, GW Radebau, Simultaneous Determination of Pseudoephedrine Hydrochloride, Chlorpheniramine Maleate, and Dextromethorphan Hydrobromide by Second-Derivative Photodiode Array Spectroscopy. J. Pharm. Sci. 47,715-718 (1988)

30. A.G. Davidson, L.M.M. Mkoji, The simultaneous assay of triprolidine, pseudoephedrine and dextromethorphan in combined preparations by derivative-difference spectrophotometry . J. Pharm. Biomed. Anal. 6, 449-460 (1988).

31. Ö.A. Dönmez, A. Bozdoğan, G. Kunt, Determination of Ternary Mixtures of Dextromethorphan Hydrobromide, Pseudoephedrine Hydrochloride and Triprolidine Hydrochloride in Syrups by Partial Least-Squares Multivariate Calibration. Reviews in Anal. Chem. 26(3), 209-217 (2007).

32. R. Jones, M.I. Orchard, K. Hall, The use of derivative and least-squares methods to analyse a polypharmaceutical product by UV spectrophotometry. J. Pharm. Biomed. Anal. 3, 335-342 (1985).

33. D. De Orsi, L. Gagliardi, A. Bolasco, D. Tonelli, Simultaneous determination of triprolidine, pseudoephedrine, paracetamol and dextromethorphan by HPLC. Chromatographia. 43, 496-500 (1996).

34. S. Furlanetto, S. Orlandini, How Experimental Design Can Improve the Validation Process. Studies in Pharmaceutical Analysis. Anal. Bioanal. Chem. 377, 937-944 (2003).

35. ICH Guide Q2 (R1). Validation of Analytical Procedures - Text and Methodology. International Conference on Harmonization of Technical Requirements for Registration of Pharmaceuticals for Human Use (ICH), Geneva, Switzerland, (2005).

36. H.T. Ting, K.A. Abou El-Hossein, H.B. Chua, J. Scientific \& Industrial Research. 6, 11 (2009).

37. G.E.P. Box, D.W. Behnken Some new three-level designs for the study of quantitative variables. Technometrics. 2, 455-475 (1960).

38. G. Derringer, R. Suich. Simultaneous Optimization of Several Response Variables. J. Qual. Technol. 12, 214219 (1980).

39. A.C. Moffat, M.D. Osselton, B. Widdop, Clarke's Analysis of Drugs and Poisons, 4th Ed., , London, England, UK: Pharmaceutical Press. (2011).

40. K. Cores, P.T. McCarthy, R.J. Flanagan, HPLC of basic drugs and quaternary ammonium compounds on microparticulate strong cation-exchange materials using methanolic or aqueous methanol eluents containing an ionic modifier. J Chromatogr A. 693, 289-306 (1995).

41. J. Ermer, E.R. Miller, Method Validation in Pharmaceutical Analysis - A Guide to Best Practice. Weinheim:WileyVCH Verlag GmbH \& Co, KGaA (2005).

42. J.R. Jenke Chromatographic method validation: A review of current practices and procedures. Part III. Ruggedness, revalidation and system suitability. J. Liq. Chromatogr. 19(12), 1873-1891 (1996).

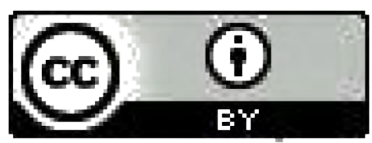

This work is licensed under a Creative Commons Attribution 4.0 International License. 